\title{
Vertical externalities with lump-sum taxes: how much difference does unemployment make?
}

Diego Martinez, Universidad Pablo de Olavide, Spain

Tomas Sjögren, Umeå University, Sweden

\begin{abstract}
This paper analyses how the existence of unemployment affects the conventional approach to vertical externalities. We discuss the optimality rule for the provision of public inputs both in a unitary and in a federal state. Our findings indicate that decentralising spending responsability on public inputs in the presence of unemployment allows output to be closer to the first best level. Moreover, we describe the inability of the federal government, behaving as a Stackelberg leader, to replicate the unitary outcome, unless there are new policy instruments at government's disposal.
\end{abstract}

\section{JEL classification}

J2; H4; H7.

\section{Keywords}

Public inputs; unemployment; vertical externalities.

\section{Acknowledgements}

We are grateful to the participants at the 20th Spanish Meeting on Public Economics, three anonymous referees and the editor for their comments. The authors would like also to thank the Spanish Ministry of Science (Projects ECO2010-15553 and ECO2010-21706), Junta de Andalucia (Projects SEJ-02479 and SEJ-6882), the Bank of Sweden Tercentenary Foundation (Stiftelsen Riksbankens Jubileumsfond), the Swedish Council for Working Life and Social Research (FAS) and the National Tax Board (Skatteverket) for research grants. 


\section{Introduction}

The standard approach to vertical externalities establishes that sharing taxes between different levels of government has an impact on efficiency. From the seminal contribution by Keen (1998), a number a papers has dealt with this issue, offering various solutions which may internalise this problem (see, for instance, Boadway and Tremblay, 2006). A common issue in all these contributions is assuming distortionary taxation.

Another common feature in this literature is the assumption of a competitive labour market, with the labour force matching exactly the demand for labour. Papers such as Dahlby and Wilson (2003) and Kotsogiannis and Martinez (2008) give a central role to the supply and demand for labour in determining equilibria but always with labour market clearing. In such a world, there is no scope for one of the conventional fiscal policies aimed at fighting unemployment, namely the provision of public inputs. In fact, to the best of our knowledge, no paper so far has dealt with vertical expenditure externalities (caused by the provision of productivity-enhancing public expenditures in a federal context) in the presence of unemployment. This has not been the case when horizontal externalities are involved (Ogawa et al, 2006).

This paper precisely combines vertical externalities and labour market imperfections in a single model. Indeed, we build a theoretical framework in which the federal government is in charge of unemployment benefits and the states provide a public input with positive effects on demand for labour. Such a theoretical framework finds some real parallells in the international evidence so long as in countries like Spain, the US or Australia (just to name a few) the allocation of spending responsibilities and taxes across tiers of government is of the kind we are considering here. Taxes are assumed to be lump-sum because we are interested in focusing on the efficiency implications derived from the expenditure side of government decisions rather than on vertical tax externalities. Anyway, we will show that ignoring distortionary taxation as a policy variable may play a crucial role for correcting the vertical externality.

The results in the paper may be summarised as follows. First, we show that, in spite of using exclusively lump-sum taxes to finance governments, a vertical expenditure externality arises when unemployment exists. This confirms a previous result found in the literature (Dahlby and Wilson, 2003; Martinez, 2008), namely, that both vertical (tax and expenditure) externalities are independent of each other. The provision of public inputs creates a positive vertical impact on federal revenues as long as this type of public spending increases the demand for labour and, therefore, it reduces the resources needed at federal level for paying unemployment benefits. And this occurs without the co-occupancy of elastic tax bases.

Moreover, we also see how the rule for the provision of public inputs at state level is closer to the production efficiency condition than that corresponding to a unitary country with a non-clearing labour market. Obviously, this does not imply that decentralisation is closer to optimality than centralisation but the fact that the assignment of distorting instruments (i. e., the public input) across different levels of government really matters for assessing optimality.

Second, we have analysed whether the federal government is able to replicate the outcome of a unitary country. As is standard in much of the earlier literature, we have assumed that the upper level government knows the states' reaction functions and therefore behaves as a Stackelberg leader vis-a-vis the state governments. Our results deviate from the earlier studies so long as the federal government has not sufficient policy instruments at its disposal to implement the unitary equilibrium. This is a consequence of using lump-sum instruments. 
In a sense, these results are related to the discussion initiated by Sato (2000), who has shown that the ability of the federal government to replicate second-best results depends on what type of policy instrument is available to the federal government. Precisely, as result of taking into consideration a new (non-lump-sum) policy instrument, i. e., a public input provided by the federal government that is complement to that offered by the states, the upper level of government is able to replicate the second-best outcome of a unitary country.

The structure of the paper is as follows. Section 2 describes the main features of the model and the different versions of the optimality rule for the provision of public inputs. Sections 3 and 4 evaluate the ability of the federal government to replicate the unitary outcome. Finally, section 5 concludes.

\section{The Basic Model}

This section aims to show two results. First, we characterise the equilibrium in a centralised country with unemployment. This allows us to see how the optimal rule for the provision of public inputs is modified in the presence of unemployment. It will also serve as a benchmark scenario with which we can compare the federal equilibria to be analysed below. Second, the benchmark model presented in this section also highlights that the fiscal decisions taken by one level of government (particularly that with spending responsibilities on public inputs) will affect the other levels of the public sector. As a consequence, vertical expenditure externalities will arise even though only lump-sum taxes are used to raise revenue in the public sector.

The theoretical framework consists of firms, households and two different tiers of government: the federal level and $k$ subnational states. ${ }^{1}$ Firms are identical across the country and, for the sake of simplicity, we assume that their number is normalised to one in each state. All of them produce a single good on the basis of the following production function:

$$
F(N, K, G)=N^{\alpha} K^{1-\alpha} G^{\beta} \text {, }
$$

where $N$ is labour, $K$ a fixed factor and $G$ a public input. Such a production technology allows us to qualify the public input as factor-augmenting. ${ }^{2}$ In this context, the public spending will increase the return to the fixed production factor $K$, which we normalised to one, in which case the profit can be expressed as:

$\pi=F(N, G)-w N$,

where $w$ is the wage rate. ${ }^{3}$ The first-order condition for profit maximisation reads $w=F_{N}(N, G)$, and it implictly defines the demand for labour as:

$N(w, G)=\alpha^{\frac{1}{1-\alpha}} G^{\frac{\beta}{1-\alpha}} w^{-\frac{1}{1-\alpha}}$

\footnotetext{
${ }^{1}$ We do not denote the states by sub-indexes for making easier the notation and given that they are assumed to be identical.

${ }^{2}$ An alternative approach would imply a production function with constant returns to scale in all the inputs (private and public). This would be the case of firm-augmenting public input. It would create economic rents that, in terms of the model we develop here, would not exhibit substantial differences with respect to what we obtain below.

${ }^{3}$ The return to labour is not affected by the public input, although this would be the normal situation with factor-augmenting public inputs. This is not the case here because we are interested in considering the impact of the public input on employment, and the demand for labour we obtain below implies that the wage rate is independent of $w(M, g)$. In a model with full-employment, however, we should set up $w(M, g)$.
} 
By combining equations (2) and (3), we obtain the profit function:

$$
\pi(w, G)
$$

We assume that all households have the same preferences for consumption $c$ across the federation and these preferences are described by a utility function $u(c)$, which is increasing in $c$. Each state is populated by three types of consumers: a firm-owner as well as employed and unemployed workers, respectively. These consumer types are denoted by the superindices "f", "e" and "u". The firm-owner is endowed with a fixed factor of production $K$, which the firmowner hires to the firm in return for the firm's profit. His budget-constraint is defined by $c^{f}=\pi-\tau^{f}$, where $\tau^{f}$ is a lump-sum tax. Regarding the other two types of consumers, we make a distinction between the total labour force available for working, $M$, and the number of households that effectively are employed $N$. Obviously, full employment is characterised by $M=N$. The budget constraint for an employed worker is $c^{e}=w-\tau^{e}$, where $\tau^{e}$ is a lump-sum tax, while the budget constraint facing an unemployed worker is given by $c^{u}=b$, where $b$ denotes a net of tax unemployment benefit.

In a centralised country, for the policy variables $\left\{\tau^{f}, \tau^{e}, b, G\right\}$, the government maximises a utilitarian welfare function

$W=k N u^{e}+k[M-N] u^{u}+k u^{f}$

subject to the following budget constraint:

$k N \tau^{e}+k \tau^{f}-k G-k[M-N] b=0$

In a situation where there is no unemployment, the first-order conditions are as follows:

$$
\begin{aligned}
& \operatorname{FOC}\left(\tau^{f}\right): \lambda=\left(u^{f}\right)^{\prime} \\
& \operatorname{FOC}\left(\tau^{e}\right): \lambda=\left(u^{e}\right)^{\prime} \\
& \operatorname{FOC}(G): F_{G}=1 \\
& \operatorname{FOC}(\lambda): N \tau^{e}+\tau^{f}-G=0,
\end{aligned}
$$

where $\lambda$ is the Lagrange multiplier associated with the government's budget constraint. The first two equations show the standard result from optimisation with lump-sum taxes and transfers: the private marginal utility (of each type of consumer) must be equal to the social welfare cost of taxation, which here is captured by the Lagrange multiplier $\lambda$. Equation (9), in turn, is the standard production efficiency condition in the provision of public inputs. Finally, (10) is the budget constraint of central government, where the last term of LHS in (6) can be dropped as there is full employment and $M=N$.

Let us now turn to the equilibrium with unemployment. It is assumed that the existence of a minimum wage, $w^{o}$, which exceeds the market-clearing wage, $w^{e}$, creates unemployment so that $M>N$. This modification will have an impact on the optimal provision of $G$. In addition, the first-order condition for the unemployment benefit $b$ must also be taken into consideration. The first-order conditions for $b$ and $G$ are 
$\operatorname{FOC}(b): \lambda=\left(u^{u}\right)^{\prime}$

$\operatorname{FOC}(G): \frac{N_{G}\left(u^{e}-u^{u}\right)}{\lambda}+N_{G} \tau^{e}+N_{G} b+F_{G}=1$.

Let us now modify the model to include different tiers of governments. We assume that the federal level is in charge of providing the unemployment benefit while the states provide the public inputs. ${ }^{4}$ Both levels of government share the tax on employed workers (with the tax rates $T^{e}$ and $t^{e}$ chosen by the federal and state governments, respectively; $\left.\tau^{e}=T^{e}+t^{e}\right)$. The revenues collected from the tax on profits are assigned in a proportion $\theta$ (which is exogenously determined) to the states $(0 \leq \theta \leq 1)$, while the tax rate $\tau^{f}$ is exclusively decided by the federal government.

In such a framework, let us assume that the states behave as Nash players, that is, each subnational government ignores the impact of its fiscal decisions on federal revenues. Therefore, the optimisation problem to be solved by the states is:

$\operatorname{Max} \quad W=N u^{e}\left(w-\tau^{e}\right)+(M-N) u^{b}(b)+u^{f}\left(\pi-\tau^{f}\right)$

$$
\begin{gathered}
\text { s.t. } \quad N t^{e}+\theta \tau^{f}-G+S=0 \\
N=N\left(w^{o}, G\right) \\
w^{o}>w^{e},
\end{gathered}
$$

where $S$ is a vertical lump-sum from the federal government to states. The last inequality refers to the distortion existing in the labour market, which is the reason for unemployment. The first-order conditions for $t^{e}, G$ and $\lambda$ give:

$$
\begin{aligned}
& \operatorname{FOC}\left(t^{e}\right): \lambda=\left(u^{e}\right)^{\prime} \\
& \operatorname{FOC}(G): \frac{N_{G}\left(u^{e}-u^{u}\right)}{\lambda}+N_{G} t^{e}+F_{G}-1=0 \equiv \Omega \\
& \operatorname{FOC}(\lambda): N t^{e}+\theta \tau^{f}-G+S=0 \equiv \Psi
\end{aligned}
$$

Observe that we, for later use, define the first-order condition for $G$ to be a function $\Omega$ whereas we also use the short notation $\Psi$ for the state government's budget constraint. Equation (14) sets up the same rule for choosing the optimal tax rate on employed workers in a centralised country as in a world with two tiers of government. This is a direct consequence of using lump-sum taxes. Even in the presence of tax sharing between different levels of government, if household behaviour is not affected by taxes, there is no scope for vertical tax externalities.

By contrast, and leaving aside the discussion on the optimal levels of $G$ (see Martinez and Sanchez (2010) for a graphical analysis and Martinez and Sjongren (2013) with a similar model to this one), let us begin by comparing the provision of the public input in a two-tier public sector (equation (15)) with the provision in a

\footnotetext{
${ }^{4}$ This distribution of spending responsabilities is not crucial for the results, which would be symmetric with an inverse vertical assignment of public expenditures. Anyway, the scheme we follow here is in line with the mainstream of theory of fiscal federalism.
} 
unitary public sector (12). The term $N_{G} t^{e}$ differs from its equivalent in (12), namely, $N_{G}\left(\tau^{e}+b\right)$. As long as the federal government implements a nonnegative lump-sum tax $T^{e}$ on employed workers, it follows that since the states decide over $G$, this tends to reduce the over-provision bias that the presence of unemployment creates in the provision of public inputs. In other words, expression (15) is closer to (9) than equation (12). ${ }^{5}$

In this regard, and contrary to the conventional view in the literature on vertical externalities, we propose here that more federalism may lead to more production efficiency. To see this in an extreme case, assume that all rent taxes accrue to the states $(\theta=1)$; the federal government needs to be financed by a negative fiscal grant (from states) and/or by charging a positive tax rate $T^{e}$ on workers. This latter solution involves an optimal rule for the provision of public inputs closer to the production efficiency condition, minimising the differential effect that the presence of unemployment creates in the discussion on optimality.

Consequently, the behaviour of federal government becomes a crucial issue to determine the effect of unemployment on the achievement of the production efficiency condition in the provision of public inputs. This is what we study in the next section.

\section{The ability of the federal government to replicate the centralised outcome}

A common way of correcting vertical (tax and expenditure) externalities is to assume that the federal government acts as a Stackelberg leader vis-a-vis the lower level governments. In such a context, the sequence of the game is as follows. First, the federal government decides on $T^{e}, \tau^{f}, S$ and, residually, on $b$, while taking into consideration the states' reactions to changes in federal policy variables. Second, the state governments determine $G$ and $t^{e}$, treating as exogenous all the decision variables of the upper-level of government. Despite the fact that the federal government is the first-mover, we are not here strictu sensu in the presence of a pure Stackelberg leader since it lacks enough policy instruments that are strategically complementary (or substitute) to the instruments of the follower(s). Under the new conditions, the optimisation problem facing the federal government can now be stated as follows:

$\operatorname{Max} \quad W=k N u^{e}\left(w-\tau^{e}\right)+k(M-N) u^{b}(b)+k u^{f}\left(\pi-\tau^{f}\right)$

s.t. $k N T^{e}+k(1-\theta) \tau^{f}-k(M-N) b-k S=0$

$G=G\left(T^{e}, \theta, \tau^{f}, S, M, N\right)$

$t^{e}=t^{e}\left(T^{e}, \theta, \tau^{f}, S, M, N\right)$

$N=N(w, G)$

$w^{o}>w^{e}$.

\footnotetext{
${ }^{5}$ It is straightforward to show that with full employment no vertical (tax and expenditure) externalities appear.
} 
Expressions (18) and (19) are the states' reaction functions. ${ }^{6}$ As written above, given that we have set up lump-sum taxes on labour income, there is no scope for vertical tax externalities. In other words, the changes in the federal tax rates do not affect the marginal cost of the public funds perceived by the state governments and, consequently, the state tax rates. Therefore, for solving the federal problem, some information on comparative statics of these reaction functions is required. To do that, we start from the first-order conditions of states (15) and (16). ${ }^{7}$ Differentiating the functions $\Omega$ and $\Psi$ (and ignoring superindex "e" for sake of simplicity in the notation) produces:

$$
\begin{aligned}
& \Omega_{G} d G+\Omega_{t} d t+\Omega_{T} d T+\Omega_{S} d S+\Omega_{\tau^{f}} d \tau^{f}=0 \\
& \Psi_{G} d G+\Psi_{t} d t+\Psi_{T} d T+\Psi_{S} d S+\Psi_{\tau^{f}} d \tau^{f}=0
\end{aligned}
$$

This two-equation system can be expressed using a matricial form as follows (and after solving for $d G$ and $d t$ ):

$$
\left(\begin{array}{c}
d G \\
d t
\end{array}\right)=-\left(\begin{array}{ll}
\Omega_{G} & \Omega_{t} \\
\Psi_{G} & \Psi_{t}
\end{array}\right)^{-1}\left(\begin{array}{lll}
\Omega_{T} & \Omega_{S} & \Omega_{\tau^{f}} \\
\Psi_{T} & \Psi_{S} & \Psi_{\tau^{f}}
\end{array}\right)\left(\begin{array}{c}
d T \\
d S \\
d \tau^{f}
\end{array}\right)
$$

From (22), we can retrieve:

$$
\begin{aligned}
& \frac{d G}{d T}=G_{T}=A\left(\Psi_{t} \Omega_{T}-\Omega_{t} \Psi_{T}\right) \\
& \frac{d G}{d S}=G_{S}=A\left(\Psi_{t^{\prime}} \Omega_{S}-\Omega_{t} \Psi_{S}\right) \\
& \frac{d G}{d \tau^{f}}=G_{\tau^{f}}=A\left(\Psi_{t^{\prime}} \Omega_{\tau^{f}}-\Omega_{t} \Psi_{\tau^{f}}\right) \\
& \frac{d t}{d T}=t_{T}=A\left(-\Psi_{g} \Omega_{T}-\Omega_{g} \Psi_{T}\right) \\
& \frac{d t}{d S}=t_{S}=A\left(-\Psi_{g} \Omega_{S}-\Omega_{g} \Psi_{S}\right) \\
& \frac{d t}{d \tau^{f}}=t_{\tau^{f}}=A\left(-\Psi_{g} \Omega_{\tau^{f}}-\Omega_{g} \Psi_{\tau^{f}}\right)
\end{aligned}
$$

where $A$ is $-\frac{1}{\Omega_{G} \Psi_{t}-\Psi_{G} \Omega_{t}}$.

Returning to the federal government's problem, it is clear that its budget constraint can be written as $b=\frac{N T^{e}+(1-\theta) \tau^{f}-S}{(M-N)}$. Plugging this into the objective function (17), we obtain the first-order conditions for the policy variables of the federal government:

\footnotetext{
${ }^{6}$ Both equations are not fundamentally reduced forms since $N=N(w, G)$; the next technical developments are, however, fully consistent with the complete definition of the functions involved.

${ }^{7}$ The first-order condition (14) can be ignored in this analysis. In a sense, this expression does not admit any influence from federal variables and, consequently, it does not matter at this point. Anyway, expression (14) can be easily inserted in (15) without modifying substantially the analysis below.
} 


$$
\begin{aligned}
& \operatorname{FOC}\left(T^{e}\right):-N\left(u^{e}\right)^{\prime}\left(1+t_{T}\right)+(M-N)\left(u^{b}\right)^{\prime}\left(b_{T}+b_{T} t_{T}+b_{G} G_{T}\right) \\
& +\left(u^{f}\right)^{\prime}\left(F_{N} N_{G} G_{T}-w N_{G} G_{T}\right)-u^{b} N_{G} G_{T}=0 \\
& \operatorname{FOO}\left(\tau^{f}\right):-N\left(u^{e}\right)^{\prime}\left(t_{\tau^{f}}\right)-u^{b} N_{G} G_{\tau^{f}}+(M-N)\left(u^{b}\right)^{\prime}\left(b_{\tau^{f}}+b_{t} t_{\tau^{f}}+b_{G} G_{\tau^{f}}\right) \\
& +\left(u^{f}\right)^{\prime}\left(F_{N} N_{G} G_{\tau^{f}}-w N_{G} G_{\tau^{f}}\right)-\left(u^{f}\right)^{\prime}=0 \\
& \text { FOC }(S):-N\left(u^{e}\right)^{\prime}\left(t_{S}\right)+(M-N)\left(u^{b}\right)^{\prime}\left(b_{S}+b_{t} t_{S}+b_{G} G_{S}\right)-u^{b} N_{G} G_{S} \\
& +\left(u^{f}\right)^{\prime}\left(F_{N} N_{G} G_{S}-w N_{G} G_{S}\right)=0 \\
& \operatorname{FOC}(\lambda): k N T^{e}+k(1-\theta) \tau^{f}-k(M-N) b-k S=0
\end{aligned}
$$

Taking into account that $b$ can be residually obtained from the above four equation-system, we simplify (29a)-(29d), which gives us the following results:

$t_{T}=0$

$t_{\tau^{f}}=-\frac{\theta}{N}$

$t_{s}=-\frac{1}{N}$

where $w=F_{N}(N, G),(23)-(25)$ and the corresponding partial derivatives of $\Omega$ and $\Psi$ (according to (15) and (16)) have been used. What is implicitly established in (30)-(32) is the inability of federal government to affect states' behaviour. One conclusion is that the federal tax rate on employed workers, $T^{e}$, has no effect on the corresponding state tax rate, $t^{e}$ (equation (30)), but also none of the policy variables of the upper level of government has any impact on the state provision of public inputs. Indeed, from expressions (23)-(25), it is clear that $G_{T}=G_{\tau^{f}}=G_{S}=0$, that is, there is no way through which the federal government can modify the provision of public inputs. The unique impact of the federal policy variables $\left(\tau^{f}\right.$ and $S$ on $\left.t^{e}\right)$ is trivial: an increase (decrease) in some of them reduces (increases) the state tax rate in a magnitude given by the number of employed workers $N$. Therefore, the highest level of government is not able to replicate not only the first-best outcome of (9) but also the optimality rule for the provision of public inputs in a unitary country with unemployment. ${ }^{8}$

\section{New instruments for the federal government: complementary public inputs}

Things may be different if the federal government is also in charge of providing a public input, $G^{F}$, which is assumed to be complementary with the state public input (now denoted $G^{S}$ ). This modification means that the model becomes more realistic in the sense that different levels of government are now jointly involved in financing complementary public infrastructure projects. This modification of the model implies that the production, profit and labour demand functions are modified as follows:

\footnotetext{
${ }^{8}$ Anyway, we must be aware that the first-best values for $T^{e}$ and $t^{e}$ are guaranteed in each scenario as long as they are lump-sum taxes.
} 


$$
\begin{aligned}
& F\left(N, K, G^{F}, G^{S}\right)=N^{\alpha} K^{1-\alpha}\left(G^{F}\right)^{\gamma}\left(G^{\beta}\right)^{\beta} \\
& \pi=F\left(N, G^{F}, G^{S}\right)-w N, \\
& N\left(w, G^{F}, G^{S}\right)=\alpha^{\frac{1}{1-\alpha}}\left(G^{F}\right)^{\frac{\gamma}{1-\alpha}}\left(G^{S}\right)^{\frac{\beta}{1-\alpha}} w^{-\frac{1}{1-\alpha}} .
\end{aligned}
$$

As before, combining (34) and (35), the profit function can be written as follows:

$$
\pi\left(w, G^{F}, G^{S}\right) \text {. }
$$

In a unitary country, the government maximises $W=k N u^{e}+k[M-N] u^{u}+k u^{f}$, subject to $k N \tau^{e}+k \tau^{f}-k G^{F}-k G^{S}-k[M-N] b=0$. In a situation characterised by full employment $(M=N)$, the optimal provision of public inputs is given by the standard production efficiency condition: $F_{G^{F}}=F_{G^{s}}=1$. By contrast, when unemployment appears as a result of non market-clearing wage rate, the first-order conditions w.r.t. $G^{F}$ and $G^{S}$ are, respectively:

$$
\begin{aligned}
& \operatorname{FOC}\left(G^{F}\right): \frac{N_{G^{F}}\left(u^{e}-u^{u}\right)}{\lambda}+N_{G^{F}} \tau^{e}+N_{G^{F}} b+F_{G^{F}}=1 \\
& \operatorname{FOC}\left(G^{s}\right): \frac{N_{G^{s}}\left(u^{e}-u^{u}\right)}{\lambda}+N_{G^{s}} \tau^{e}+N_{G^{s}} b+F_{G^{s}}=1
\end{aligned}
$$

It is straightforward to show that when the government is concerned with the level of employment, if the effect of, say, the state public input on labour demand is higher than the equivalent effect by the federal public input $\left(N_{G^{s}}>N_{G^{F}}\right)$, then the optimal amount of $G^{S}$ will exceed $G^{F}$.

In a decentralised environment, in which both the federal and the state governments behave as Nash competitors, the first-order conditions for $G^{F}$ and $G^{S}$ are, respectively:

$$
\begin{aligned}
& \operatorname{FOC}\left(G^{F}\right): \frac{N_{G^{F}}\left(u^{e}-u^{u}\right)}{\lambda}+N_{G^{F}} T^{e}+N_{G^{F}} b+F_{G^{F}}=1 \\
& \operatorname{FOC}\left(G^{s}\right): \frac{N_{G^{s}}\left(u^{e}-u^{u}\right)}{\lambda}+N_{G^{S}} t^{e}+N_{G^{s}} b+F_{G^{s}}=1
\end{aligned}
$$

Comparing these expressions with (36) and (37), it is clear that both types of public inputs will be underprovided if governments set positive tax rates on employed workers. Under these circumstances, the levels of $G^{F}$ and $G^{S}$ will be below the optimal ones derived from a centralised setting. In other words, each level of government decides a level of public input without considering its impact on other jurisdictions. Consequently, there now exists a double vertical expenditure externality from each level of government to the other.

The question now is whether the federal government, behaving as Stackelberg leader, is able to replicate the second-best outcome. Recall that the answer to this question was "no" in a setting in which the federal instruments were $T^{e}, \tau^{f}, S$ and $b$. With the federal government also providing a public input, its optimisation problem is now: 


$$
\begin{aligned}
& \text { Max } \quad W=k N u^{e}\left(w-\tau^{e}\right)+k(M-N) u^{b}(b)+k u^{f}\left(\pi-\tau^{f}\right) \\
& \text { s.t. } k N T^{e}+k(1-\theta) \tau^{f}-k(M-N) b-k G^{F}-k S=0 \\
& G^{S}=G\left(T^{e}, \theta, \tau^{f}, S, M, N, G^{F}\right) \\
& t^{e}=t^{e}\left(T^{e}, \theta, \tau^{f}, S, M, N, G^{F}\right) \\
& N=N\left(w, G^{s}, G^{F}\right) \\
& w^{o}>w^{e} .
\end{aligned}
$$

Note that the states' reaction functions (41) and (42) now include a new argument: the federal public input $G^{F}$. As before, we first need to know some comparative statics of these functions. Equations (23)-(28) are still valid in the new context -with a slight change: the term $A$ must be substituted by $A^{\prime}$-(see below)- and we only have to add the corresponding response of $G^{S}$ and $t^{e}$ to the new federal policy instrument $G^{F}$. Particularly, we can write:

$$
\begin{aligned}
& \frac{d G^{S}}{d G^{F}}=A^{\prime}\left(\Psi_{t} \Omega_{G^{F}}-\Omega_{t} \Psi_{G^{F}}\right) \\
& \frac{d t}{d G^{F}}=A^{\prime}\left(-\Psi_{G^{S}} \Omega_{G^{F}}-\Omega_{G^{S}} \Psi_{G^{F}}\right),
\end{aligned}
$$

where $A^{\prime}$ is $-\frac{1}{\Omega_{G} \Psi_{t}-\Psi_{G} S \Omega_{t}}$.

In this regard, a significant difference appears when comparing these new results with the previous ones. While in Section 3 the federal government only had a very limited (and trivial) impact on state tax rate ${ }^{t}$ (recall expressions (30)-(32) and the fact that $G_{T}=G_{\tau^{f}}=G_{S}=0$ ), things are now quite different. Consider first the case of $\frac{d G^{S}}{d G^{F}}$; after some algebra manipulations it can be seen that the effect of changes in the federal public input on the state provision of public inputs is given by:

$$
\frac{d G^{S}}{d G^{F}}=-\frac{\left(N_{G^{S} G^{F}}\left(u^{e}-u^{u}\right) / \lambda\right)+N_{G^{s} G^{F}} t+F_{G^{s} G^{F}}}{\left(N_{G^{S} G^{S}}\left(u^{e}-u^{u}\right) / \lambda\right)+N_{G^{s} G^{s}} t+F_{G^{s} G^{s}}}>0 .
$$

This means that an increase in the federal public input encourages the provision of the state public input. That is, there is an additional channel through which the federal government can affect states' behaviour. In the case of the state tax rate, something similar happens:

$$
\frac{d t}{d G^{F}}=-\frac{t}{N}\left(N_{G^{S}} \frac{d G^{s}}{d G^{F}}-N_{G^{F}}\right)>=<0 .
$$

But here the effect of federal public input on state policy variable is not so clear. Indeed, an increase in the federal public input may lead to either an increase or a decrease in the state tax rate on employed workers. Anyway, it is worth noting that again federal government may affect states' behaviour, which was not possible under the previous assumptions.

Given this, the first-order condition for the optimal provision of $G^{F}$ is as follows: 


$$
\begin{aligned}
& \text { FOC }\left(G^{F}\right): \frac{N_{G^{F}}\left(u^{e}-u^{u}\right)}{\lambda}+\frac{N_{G^{s}} \frac{d G^{S}}{d G^{F}}\left(u^{e}-u^{u}\right)}{\lambda}-N \frac{d t}{d G^{F}}+ \\
& +N_{G^{F}} T+N_{G^{S}} \frac{d G^{S}}{d G^{F}} T+b\left(N_{G^{F}}+N_{G^{S}} \frac{d G^{S}}{d G^{F}}\right)=1 .
\end{aligned}
$$

After some algebra manipulations, it can be shown that to replicate the secondbest condition (36) requires to hold:

$$
N_{G^{S}} \frac{d G^{s}}{d G^{F}}\left(\frac{u^{e}-u^{u}}{\lambda}-\tau+b\right)=F_{G^{F}} .
$$

If the individual utility is assumed to be linear $(u(c)=c)$, it is straightforward to prove that both sides of expression (46) have the same sign. Hence, to replicate the second best outcome for the provision of public inputs is a real possibility when federal government can spend money in public inputs which are complementary to state public inputs.

\section{Concluding remarks}

Vertical externalities usually involve challenges for efficiency in federal countries. Sharing taxes between different levels of government or the provision of certain public expenditures with effects on other tiers of government revenues imply deviations from the optimality rules, which would be obtained in a centralised world. However, the presence of vertical (tax and expenditure) externalities can be disregarded if lump-sum taxes are used. Indeed, the idea of governments affecting fiscal decisions taken by others requires distorting taxes able to modify households' behaviour.

All these general statements have to be qualified in the presence of unemployment, and this has been what we have done in this paper. Particularly, we have built a simple model with lump-sum taxes and unemployment in which the optimal rule for the provision of public inputs depends on whether the structure of the country is federal or not. Indeed, while there is no scope for vertical tax externalities (the fact of using lump-sum taxes here is crucial), a deviation from the second-best outcome takes place when states are in charge of the provision of productivity-enhancing public factors and the federal government finances unemployment benefits.

We have confirmed that the optimality condition for the provision of public inputs must consider the impact of this type of public expenditure on employment and, consequently, on public spending in unemployment benefits. As the production efficiency condition for public inputs is not satisfied even in the case of a centralised country, we have analysed what would occur when states behaving as Nash players take part in the game. Since sub-national governments do not take into account the effect of their public expenditures on unemployment benefits, the over-provision of public inputs (compared to the first-best case with full employment) is lower with a federal structure than in a unitary country.

When we have wondered about the capability of federal government to replicate the outcome of a unitary country, we have assumed that the upper level of government behaves as a Stackelberg leader, considering the states' reaction functions. Under such a scenario, we have concluded that, unlike previous papers, federal government is not able to internalise the vertical expenditure externality. Federal policy variables have no impact on states' decision variables.

In part, this is caused by using lump-sum taxes; indeed, distortionary taxation can affect agents' behaviour and this is the way through which all the effects of public inputs can be internalised. By contrast, when the federal government is also in 
charge of providing a public input which is complementary to the state public input, it is possible to replicate the second-best outcome for the optimal provision of such as public inputs.

A number of issues arise for further research. Asymmetries at regional level in the federation can be taken into consideration. Given our federal budget constraint, the characterisation of equilibria may then involve that not all the resources collected by the upper level of government in a region must be spent in such territory; consequently, some possibilities for horizontal redistribution arise and even for explicit equalisation schemes. Also under this framework, in the presence of mobile production factors, phenomena of tax competition may take place, with the consequent effects on efficiency and regional labour markets. A third avenue for further research could be based on an alternative way for including unemployment in the model. Let think us, for instance, of a system of generous enough unemployment benefits and in which the workers take labour decisions.

As a policy implication we would underline how important the coordination of different levels of government is to attain social welfare gains. Indeed, the design of federal and state fiscal policies must take into account the magnitude of their cross effects on the tax revenues of other tiers of government. Particularly, this is true in the case of public infrastructure because this type of government expenditure is very vulnerable to public spending cuts and its benefits are very visible. Increasing the coordination in the provision of public transport infrastructure (some roads may be provided at the regional level, whereas railways may be provided by the federal government) translates into more social welfare, part of which will be in terms of employment. This would be especially appropriate in countries like Spain, where the unemployment rates have reached extraordinarily high values in the aftermath of the Great Recession.

This is especially pertinent in the context of fiscal austerity of many developed countries in the aftermath of this recession. Growth-enhancing policies such as those related to public infrastructure projects are able to generate positive fiscal externalities in the form of reduced public spending in unemployment benefits and increased tax revenues from labour taxation. This is a valuable benefit that should not be underestimated when designing economic policies.

\section{References}

Boadway, Robin and Jean-François Tremblay (2006) 'A theory of fiscal imbalance', FinanzArchiv/Public Finance Analysis 62 (1): 1-27.

Dahlby, Bev and Leonard S. Wilson (2003) 'Vertical fiscal externalities in a federation', Journal of Public Economics 87(5/6): 917--930.

Keen, Michael (1998) 'Vertical tax externalities in the theory of fiscal federalism', IMF Staff Papers 45 (3): 454-485.

Kotsogiannis, Christos and Diego Martinez (2008) 'Ad valorem taxes and the fiscal gap in federations', Economics Letters 99 (3): 431-434.

Martinez, Diego (2008) 'Optimal federal taxes with public inputs', FinanzArchiv /Public Finance Analysis 64(4): 422-433.

Martinez, Diego and A. Jesús Sanchez (2010) 'A note on the optimal level of public inputs', Social Choice and Welfare 34(3): 363-369.

Martinez, Diego and Tomas Sjongren (2013) 'Can labor market imperfections cause overprovision of public inputs?', Journal of Economic Research, 18 (2): 135 146.

Ogawa, Hikaru, Yasuhiro Sato and Toshiki Tamai (2006) 'A note on unemployment and capital tax competition', Journal of Urban Economics 60(2): 350-356. 
Sato, Motohiro (2000) 'Fiscal externalities and efficient transfers in a federation', International Tax and Public Finance, 7:119-139. 